\title{
Initial Discectomy Associated with Aging Leading to Adjacent Disc Disease and Recurrence
}

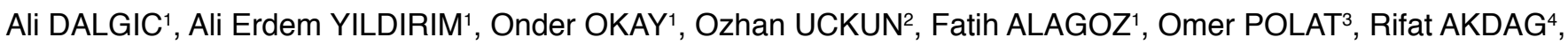 \\ Osman NACAR ${ }^{1}$, Ergun DAGLIOGLU ${ }^{1}$, Deniz BELEN ${ }^{1}$
}

\begin{abstract}
${ }^{1}$ Ankara Numune Educational and Training Hospital, II. Neurosurgery Clinic, Ankara, Turkey
${ }^{2}$ Eskisehir Yunus Emre State Hospital, Neurosurgery Clinic, Eskişehir, Turkey

${ }^{3}$ Fatma Hatun Private Hospital, Neurosurgery Clinic, Bolu, Turkey

${ }^{4}$ Şevket Yılmaz Research and Training Hospital, Neurosurgery Clinic, Bursa, Turkey
\end{abstract}

This paper was presented in $27^{\text {th }}$ Annual Meeting of the AANS/CNS Section on Disorders of the Spine and Peripheral Nerves on March 09-12, 2011, in Phoenix, Arizona, USA."

\section{ABSTRACT}

AIM: Failure of surgery for lumbar disc herniation (LDH) can be commonly caused by recurrence. There are many debates regarding the risk factors of recurrent $\mathrm{LDH}(\mathrm{rLDH})$ and it is very difficult to define them because many clinical and complicated biomechanical parameters are involved. The purpose of study was to evaluate the long term result of re-discectomy for LDH at the same level and adjacent segments.

MATERIAL and METHODS: Between 1999 and 2009, 1898 cases were operated and 142 (6.4\%) patients underwent re-discectomy following initial operation. The study included 65 patients who were operated for single level discectomy, and their charts were analyzed retrospectively.

RESULTS: There were $33(50.8 \%)$ women and mean age was 45.5 years (24-73 years). rLDH was diagnosed at the initial level in 40 $(61.5 \%)$ but adjacent and/or opposite level herniation (with or without the first level) was found in the remaining 25 cases (39.1\%). Recurrence at the same level (SLG) and adjacent level groups (ALG) were similar according to the clinical outcomes in follow-up (mean 34.1 months). Admission period after initial operation was also parallel in SLG and ALG (54.7 and 53.1 months, respectively). However, the mean age of ALG (49.4 years) was significantly higher ( $\mathrm{p} \leq 0.05)$ than SLG (42.8 years).

CONCLUSION: After discectomy, collapsed discs are biomechanically more stable than those with preserved disc heights, and responses to axial compression on intervertebral disc pressure produced deformations of adjacent levels despite limitations.

Altered biomechanical loading next to a fusion resulted in ongoing degeneration with aging at the affected entire lumbar spine.

KEYWORDS: Lumbar disc herniation, Reccurence, Adjacent segment, Aging

\section{INTRODUCTION}

Lumbar discectomy is the most common surgical procedure performed by spine surgeons for patients complaining of back and leg pain. Numerous new techniques have been used to improve the efficacy of the surgical excision of herniated intervertebral discs but these procedures still include some difficulties, especially the persistence and recurrence of symptoms. Failure of surgical treatment for LDH can be caused by the true recurrence of disc herniation, new disc herniation at a different disc level, epidural fibrosis, arachnoiditis, foraminal stenosis, and segmental instability $(8,21-23,29,30,32)$. The overall rate of unsatisfactory discectomy results range from $5 \%$ to $20 \%$ of recurrent disc herniation and it is the major 
source of disability which was reported to be seen in $5 \%$ to $11 \%$ of patients $(8,21,29,32)$. The rate of repeat interventions following primary discectomy ranges from $4 \%$ to $18 \%(7,12$, $21,28)$.

There is constant debate on the risk factors of recurrent $\mathrm{LDH}(\mathrm{rLDH})$ and it is quite difficult to define them, because many clinical and complicated biomechanical parameters are involved. Many studies have revealed multiple risk factors for rLDH, such as disc degeneration, head injury, age, smoking, gender, and obesity $(6,28,29)$. Kim et al. reported old age, high body mass index (BMI), protrusion type disc, and positive Modic change as risk factors (16). Carragee et al. found that the degree of annular competence after a discectomy and the type of herniation were correlated with the recurrence rates after discectomies (5). However, these factors did not reflect the biomechanical stress on the affected disc level and joint and might be related to $\mathrm{rLDH}$.

We aim to assess the long-term evaluation of successive surgeries for rLDH while comparing the incidence of recurrence other than the involved levels such as contralateral, bilateral or adjacent segments.

\section{MATERIAL and METHODS}

Between September 1999 and December 2009, 1898 cases with the diagnosis of lumbar disc herniation were operated at our center. 142 (6.4\%) patients underwent a reoperation procedure following a previous lumbar discectomy. One hundred-twenty two patients were followed-up and their charts were reviewed in a retrospective manner. Sixty five patients were operated for single level discectomy who met the inclusion criteria were enrolled in the study; and 57 cases were excluded for various reasons: 43 had concomitant spinal stenosis with multilevel disc herniations, 3 suffered from severe weakness and/or cauda equina syndrome after the previous surgery and emergency surgery was performed, 1 had surgical failure at the wrong level, 2 had disc herniation at a different level, and 8 had less than 6 months of pain relief. The criteria for inclusion: 1) minimum 6 months or more pain relief after primary disc surgery, 2) a true recurrent disc herniation at the same level and side or adjacent level, and 3) the presence of recurrent radicular pain that was unresponsive to conservative treatment, so that a repeat operation was performed.

Patients were divided into two groups: The first group was the same level group (SLG) who received repeat laminotomies and discectomies at the same level and ipsilaterally alone. The second one was the adjacent level group (ALG) who underwent repeat surgery concomitants with the adjacent segment and/or same level. The overall results after revision surgery were assessed. Improvement of preoperative symptoms and overall postoperative outcomes among the groups were assessed and a $p$ value less than 0.05 were set to be significant. The difference in terms of age, recurrence-free period and the visual analogue scale (VAS) score of the patient group were analyzed with Student's paired $t$ test and Tukey test just before surgery and at the last follow-up.

\section{RESULTS}

There were 32 men (49.2\%) and 33 women (50.8\%), with a mean age of 45.5 years (range, 24-73 years). All patients experienced symptoms due to recurrent radicular pain and a positive Laseque's test. Contrast enhanced MRI was performed for diagnostic purposes in all cases, and CT was also performed in 22 cases. The distribution of the levels of disc herniation was as follows: 1 at L2-L3, 6 at L3-L4, 31 at L4-L5, and 27 at L5-S1 on the first operation. The distribution of the operation levels are shown in Table I.

Among the first group, 40 patients underwent the same level/ same side operation (Figure 1A, B). In the second group, 22 underwent the same and adjacent level operation, and 3 were operated on at the adjacent segment alone. rLDH was diagnosed at an same level group (SLG) in 40 (61.5\%) patients, and adjacent level or opposite side herniation group (ALG) were found (with or without the first level) in the remaining 25 cases (Figures 2A-C; 3A-C) (Table II). The recurrence-free period after the initial operation was parallel in SLG and ALG groups (54.7 and 53.1 months, respectively). The preoperative VAS score was detected as 9.08 (range 6-10) and 2.33 (range 0-5) after surgery. Clinical outcomes in SLG and ALG were similar according to VAS in follow-up; however, the mean age of ALG (49.4) was significantly higher $(p<0.05)$ than mean age of SLG (42.8) (Table III).

\section{DISCUSSION}

Trauma, age, smoking, gender, and obesity were found to aggravate rLDH as risk factors $(2,5,7,12,17,22,28,32)$. After the discectomy, biomechanical stress on the affected level also caused rLDH. Therefore an altered biomechanical

Table I: Distribution of Primary and Re-Operation Levels

\begin{tabular}{lcc}
\hline & $\begin{array}{c}\text { Previous operation } \\
\text { level }\end{array}$ & $\begin{array}{c}\text { Re-operation } \\
\text { level }\end{array}$ \\
\cline { 2 - 3 } & $\mathbf{n}(\%)$ & $\mathbf{n}(\%)$ \\
\hline L2-3 & $1(1.5)$ & - \\
\hline L3-4 & $6(9.2)$ & $2(3.1)$ \\
\hline L3-4,L4-5 & - & $5(7.7)$ \\
\hline L4-5 & $31(47.7)$ & $25(38.5)$ \\
\hline L4-5,L5-S1 & - & $16(24.6)$ \\
\hline L5-S1 & $27(41.5)$ & $17(26.2)$ \\
\hline
\end{tabular}

Table II: Distribution of Reoperated Levels for Same and Adjacent Segments

\begin{tabular}{lcc}
\hline & Frequency & Percent \\
\hline Same Level Group (SLG) & 40 & 61.5 \\
\hline Adjacent Level Group (ALG) & 25 & 38.5 \\
\hline Total & 65 & 100 \\
\hline
\end{tabular}


condition reflected adjacent disc levels and deteriorated "segmental biomechanics," as well as an exacerbation of the degenerative process. In this study, the recurrence site of disc herniation was analyzed after the primary discectomy and the mean age of ALG (49.4 years) was higher than SLG (42.8 years) due to the discectomy's acceleration of the degenerative situation.
Early results of surgical discectomy have shown success rates of over $90 \%$; however long-term results were less positive with success rates of $40 \%$ to $79 \%$ at a follow-up of 7 year or more (21). In the studies comparing the outcome of operative and conservative treatments, there was no significant difference between the final results of surgical and nonsurgical treatment after both 10 and 20 years of observation (30). Recently, the

Table III: Relationship Between the Recurrence Level and Age, Recurrence Free Time and Follow-Up Period

\begin{tabular}{lccccc}
\hline & \multicolumn{2}{c}{ Same level group } & \multicolumn{2}{c}{ Adjacent level group } & \multirow{2}{*}{$\mathbf{p}$} \\
\cline { 2 - 5 } & $\mathbf{X} \pm$ SD & median & $\mathbf{X} \pm$ SD & median & \\
\hline Age (years) & $42.9 \pm 10$ & $44(27-65)$ & $49.4 \pm 12.6$ & $51(24-73)$ & $\mathbf{0} 0.039$ \\
\hline Recurrence Free Time (months) & $54.75 \pm 47.4$ & $48(7-192)$ & $53.1 \pm 48.4$ & $36(7-180)$ & 0.995 \\
\hline Follow-up (months) & $34.5 \pm 22.5$ & $29(4-94)$ & $33.5 \pm 22.8$ & $28(4-94)$ & 0.866 \\
\hline
\end{tabular}

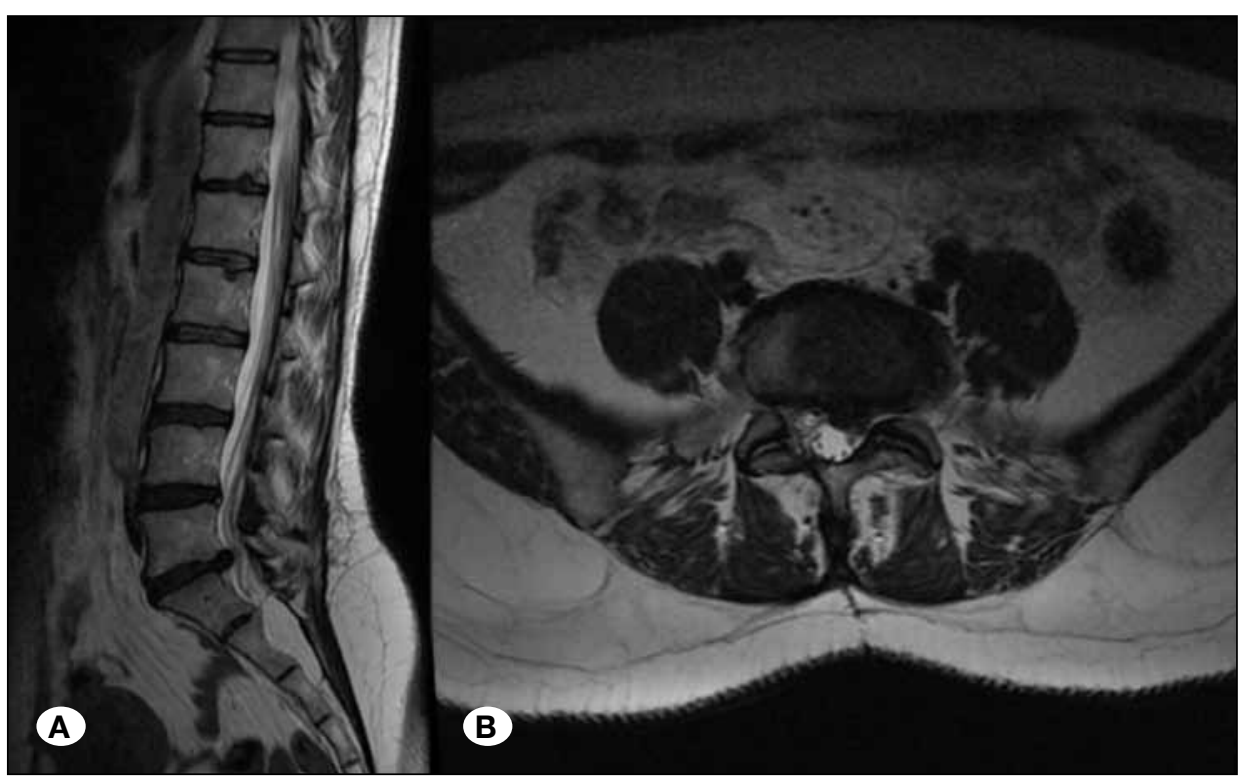

Figure 1: MR images show recurrent disc herniation at same level - opposite side (A). Defects of hemilaminectomy were seen at the right side, but the recurrence herniation at the left side (B).

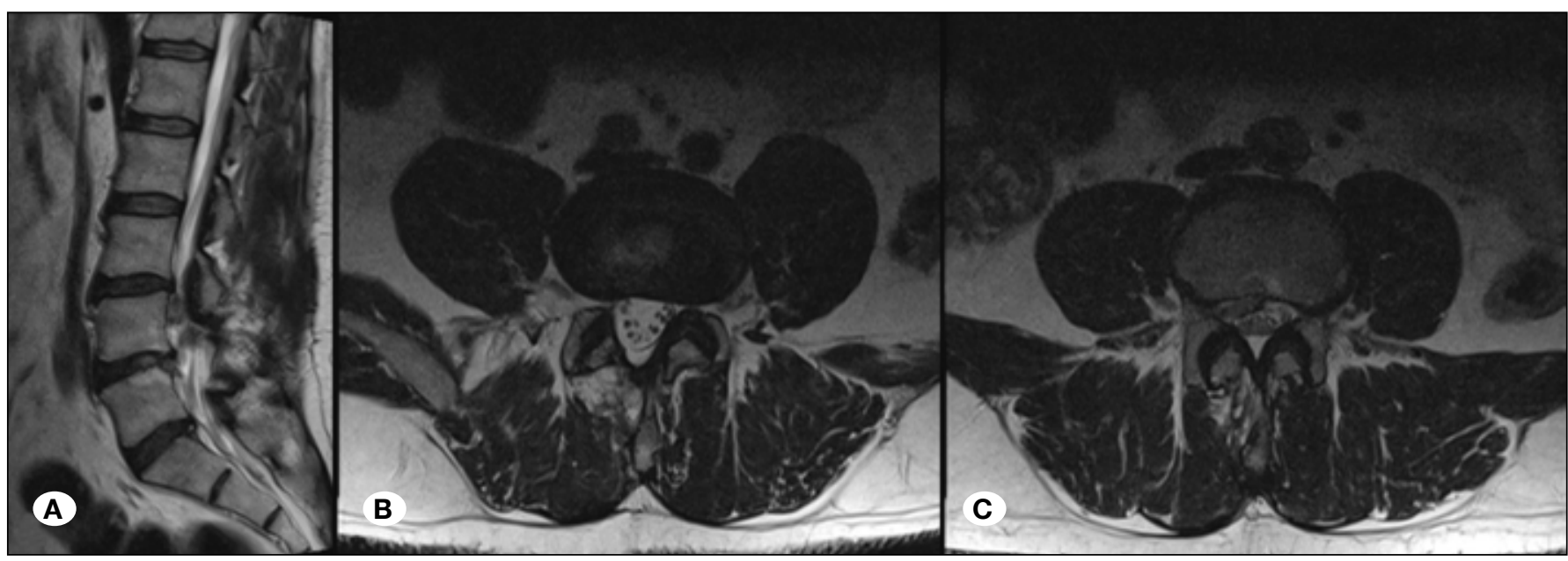

Figure 2: MR images revealed the disc herniation at upper level - same side (A). Hemilaminectomy was seen at level of L4-5 and the right side (B), but the disc herniation occured at L3-4 and same side (C). 


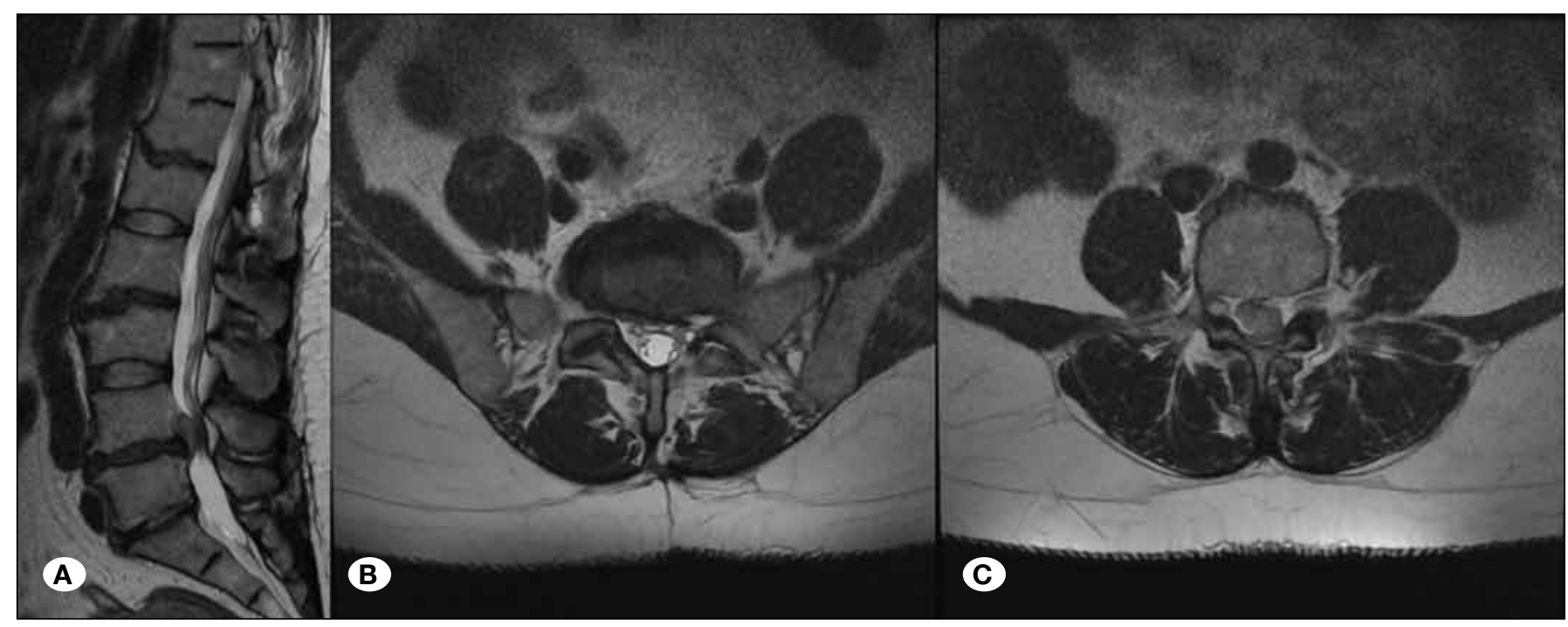

Figure 3: MR images show the disc herniation at lower level - opposite side (A). Hemilaminectomy was seen at the level of L5-S1 and the left side (B), but the disc herniation occured at L4-5 and the opposite side (C).

patients with surgical treatment had more complete relief of leg pain and improved function and satisfaction compared with patients who were initially treated non-surgically over 10 years (1). However, improvement in the patient's predominant symptom, work, and disability outcomes was still similar, regardless of the surgical treatment received (1). Whether the outcome of lumbar discectomies in the long term is actually the "result" of surgery or simply the natural history of the underlying degenerative process should be a matter of discussion. The concept of the progression of disc degeneration consists of dysfunction, unstable, and re-stabilization phases (18).

Degeneration of the disc has a complex multifactorial etiology, and most evidence points to an age-related process influenced primarily by mechanical and genetic factors (14). There is a high incidence of apoptosis in the intervertebral disc with aging. The surviving cells are not synthetically inactive, but rather produce inappropriate matrix products during aging and degeneration (11). Disc degeneration is related to mechanical stresses and may begin in early adulthood and progress through the aging process. In healthy individuals, the stress is transmitted from the center of the endplate whereas in a degenerative state stress is transmitted more to the peripheral rather than the central aspects of the vertebral body. This is thought to be due to the loss of nucleus pulposus hydration that accompanies aging (13). Moreover, nucleotomy results in decreased disc pressure, decreased endplate deformation, and modified loading patterns onto the inferior vertebra in compression loading (10). Barth et al. reported a significant increase in endplate degeneration and disc dehydration following discectomies (3). A standard open discectomy involving incising the annulus and removal of the nucleus pulposus increased disc degeneration, and the loss of height of the operative disc space also frequently occurs after the surgery (23), as demonstrated in our technique.

Progressive disc degeneration and height loss at the level of discectomy occur in most patients and, in fact, contribute to post-discectomy mechanical back pain in a subset of them $(4,21,25,32)$. Biomechanical studies support the notion that increased disc disruption will accelerate degenerative disc disease and radially transfer axial loads to the posterior column facet joints (20-22). Pathological changes, such as facet joint degeneration, progressive endplate degeneration, loss of disc height and lumbar instability are being increasingly recognized as important contributors to unfavorable patient outcomes $(4,19,24,31)$. As these pathological changes were correlated with excessive resection of both bony structures (such as facet joints) and soft tissues (such as ligaments and degenerated disc material); eventually, the symptoms due to accelerated degeneration might be found within 2 years (4). Yorimitsu et al. found a $25 \%$ loss of disc height in most patients 1 year after a lumbar discectomy (32). McGirt et al. also showed an average of $26 \%$ height loss of the operative disc space 2 years after a primary lumbar discectomy (23).

We found the rate of true lumbar disc herniation as 6.4 percent in our series. This study includes 65 cases that were previously operated on single level herniation. Forty patients (SLG - 61.5\%) need treatment at the same level however 25 cases (ALG - 38.5\%) necessitated a revision surgery for LDH detected at adjacent level or opposite side with or without initial level. Although recovery rates and recurrence free periods were similar in these groups, mean age of ALG was higher than SLG with a statistically significance. We believe that discectomy accelerates the degeneration process and aging has been a part of the process.

There is a possibility that the disc degeneration further progresses with extreme physical overload, such as that required for recreational sports or daily work. The subsequent disc narrowing might induce discogenic low back pain (LBP) and spondylotic changes in the facet joints and spur formation in the vertebral body, which may aggravate LBP further (32). Compressive deformations increase with age as disc pressure falls, but deformations appear to be limited by impaction of 
adjacent neural arches and total compressive deformations are sufficient to cause foraminal stenosis (26).

The long-term radiological results revealed that degeneration of the operated disc was a general finding, and the operation cannot prevent the obvious further degeneration of the lumbar discs (27). Axelsson and Karlsson reported that restabilization stage begins when the disc height is reduced by $50 \%$ (2). Hasegawa et al. demonstrated that degenerative segments with preserved disc height have a latent instability compared to segments with collapsed discs (15). Kim et al. also suggested that collapsed discs are biomechanically more stable than those with preserved disc height, resulting in a low incidence of rLDH (17). However, a stable segment is associated with immobilization of the regarding segment which might induce an overload to the adjacent segments. In conclusion, the change in the biomechanical load adjacent to the fused segment causes a significant overload; underlying degenerative disease together with aging can affect the entire lumbar spine after the surgery.

Degenerative disc disease depends on the accumulation of environmental factors such as aging, changing of biomechanical duration and its insults and low-level injuries (6). However, recent studies suggest that there is an association between genetic influences and disc degeneration. Moreover, the risk of developing degenerative disc disease increased up to six times compared to the general population (6). Eser et al. revealed that short repeated alleles of the aggrecan gene were significantly associated with disc degeneration and multilevel disc degeneration. Their study showed that short repeated alleles of the aggrecan gene are correlated with increased degenerative disc disease in Turkish population (9). A limitation of our study is that we did not analyze the crossover of genes in the patients. On the other hand, we believe that environmental factors have a more dominant influence than genetic changes. Further studies should compare the genetic and environmental factors.

\section{- CONCLUSION}

Discectomy accelerates the degenerative process associated with aging and the responses of the operated disc/vertebral body unit to axial compression are transferred to adjacent segments. Surgery alters the biomechanics of the functional motion segment and results in additional disc herniation at the adjacent level or the opposite side more commonly than expected.

\section{REFERENCES}

1. Atlas SJ, Keller RB, Wu YA, Deyo RA, Singer DE: Long-term outcomes of surgical and nonsurgical management of sciatica secondary to a lumbar disc herniation: 10 year results from the maine lumbar spine study. Spine 30: 927-935, 2005

2. Axelsson $P$, Karlsson BS: Intervertebral mobility in the progressive degenerative process: A radiostereometric analysis. Eur Spine J 13:567-572, 2004
3. Barth M, Diepers M, Weiss C, Thome C: Two-year outcome after lumbar microdiscectomy versus microscopic sequestrectomy: Part 2: radiographic evaluation and correlation with clinical outcome. Spine 33:273-279, 2008

4. Barth $\mathrm{M}$, Weiss $\mathrm{C}$, Thomé C: Two-year outcome after lumbar microdiscectomy versus microscopic sequestrectomy: Part 1: evaluation of clinical outcome. Spine 33:265-272, 2008

5. Carragee EJ, Han MY, Suen PW, Kim D: Clinical outcomes after lumbar discectomy for sciatica: The effects of fragment type and anular competence. J Bone Joint Surg Am 85-A: 102-108, 2003

6. Chan D, Song Y, Sham P, Cheung KM: Genetics of disc degeneration. Eur Spine J 15 Suppl 3: S317-325, 2006

7. Cinotti G, Roysam GS, Eisenstein SM, Postacchini F: Ipsilateral recurrent lumbar disc herniation. A prospective, controlled study. J Bone Joint Surg Br 80:825-832, 1998

8. Dora C, Schmid MR, Elfering A, Zanetti M, Hodler J, Boos $\mathrm{N}$ : Lumbar disk herniation: Do MR imaging findings predict recurrence after surgical diskectomy? Radiology 235:562567, 2005

9. Eser O, Eser B, Cosar M, Erdogan MO, Aslan A, Yıldız H, Solak M, Haktanır A: Short aggrecan gene repetitive alleles associated with lumbar degenerative disc disease in Turkish patients. Genet Mol Res 30:1923-1930, 2011

10. Frei $H$, Oxland TR, Rathonyi GC, Nolte LP: The effect of nucleotomy on lumbar spine mechanics in compression and shear loading. Spine 26:2080-2089, 2001

11. Gruber HE, Hanley EN Jr: Analysis of aging and degeneration of the human intervertebral disc. Comparison of surgical specimens with normal controls. Spine 23:751-757, 1998

12. Guo JJ, Yang H, Tang T: Long-term outcomes of the revision open lumbar discectomy by fenestration: A follow-up study of more than 10 years. Int Orthop 33:1341-1345, 2009

13. Hadjipavlou AG, Simmons JW, Pope MH, Necessary JT, Goel VK: Pathomechanics and clinical relevance of disc degeneration and annular tear: A point-of-view review. Am J Orthop 28:561-571, 1999

14. Hadjipavlou AG, Tzermiadianos MN, Bogduk N, Zindrick MR: The pathophysiology of disc degeneration: A critical review. J Bone Joint Surg Br 90:1261-1270, 2008

15. Hasegawa K, Kitahara K, Hara T, Takano K, Shimoda H, Homma T: Evaluation of lumbar segmental instability in degenerative diseases by using a new intraoperative measurement system. J Neurosurg Spine 8: 255-262, 2008

16. Kim JM, Lee SH, Ahn Y, Yoon DH, Lee CD, Lim ST: Recurrence after successful percutaneous endoscopic lumbar discectomy. Minim Invasive Neurosurg 50:82-85, 2007

17. Kim KT, Park SW, Kim YB: Disc height and segmental motion as risk factors for recurrent lumbar disc herniation. Spine 34: 2674-2678, 2009

18. Kirkaldy-Willis WH, Farfan HF: Instability of the lumbar spine. Clin Orthop Relat Res 165:110-123, 1982

19. Kjaer P, Leboeuf-Yde C, Korsholm L, Sorensen JS, Bendix T: Magnetic resonance imaging and low back pain in adults: A diagnostic imaging study of 40 -year-old men and women. Spine 30: 1173-1180, 2005 
Dalgic A. et al: Recurrence on Adjacent Disc Level

20. Kowalski JM, Olsewski JM, Simmons ED Jr: Results of intervertebral diskectomy without fusion at L4-5 versus L5S1. J Spinal Disord 8: 457-463, 1995

21. Loupasis GA, Stamos K, Katonis PG, Sapkas G, Korres DS, Hartofilakidis G: Seven- to 20-year outcome of lumbar discectomy. Spine 24: 2313-2317, 1999

22. McGirt MJ, Ambrossi GL, Datoo G, Sciubba DM, Witham TF, Wolinsky JP, Gokaslan ZL, Bydon A: Recurrent disc herniation and long-term back pain after primary lumbar discectomy: Review of outcomes reported for limited versus aggressive disc removal. Neurosurgery 64:338-345, 2009

23. McGirt MJ, Eustacchio S, Varga P, Vilendecic M, Trummer M, Gorensek M, Ledic D, Carragee EJ: A prospective cohort study of close interval computed tomography and magnetic resonance imaging after primary lumbar discectomy: Factors associated with recurrent disc herniation and disc height loss. Spine 34:2044-2051, 2009

24. Mochida J, Nishimura K, Nomura T, Toh E, Chiba M: The importance of preserving disc structure in surgical approaches to lumbar disc herniation. Spine 21:1556-1563, 1996

25. Parker SL, Xu R, McGirt MJ, Witham TF, Long DM, Bydon A: Long-term back pain after a single-level discectomy for radiculopathy: incidence and health care cost analysis. J Neurosurg Spine 12:178-182, 2010
26. Pollintine P, van Tunen MS, Luo J, Brown MD, Dolan P, Adams MA: Time-dependent compressive deformation of the ageing spine: relevance to spinal stenosis. Spine 35:386-394, 2010

27. Poussa M, Schlenzka D, Mäenpää S, Merikanto J, Kinnunen $P$ : Disc herniation in the lumbar spine during growth: Longterm results of operative treatment in 18 patients. Eur Spine $\mathrm{J}$ 6: 390-392, 1997

28. Suk KS, Lee HM, Moon SH, Kim NH: Recurrent lumbar disc herniation: Results of operative management. Spine 26:672676, 2001

29. Swartz KR, Trost GR: Recurrent lumbar disc herniation. Neurosurg Focus 15:E10, 2003

30. Weber $\mathrm{H}$ : Lumbar disc herniation: A controlled, prospective study with ten years of observation. Spine 8:131-140, 1983

31. Wenger M, Mariani L, Kalbarczyk A, Groger U: Long-term outcome of 104 patients after lumbar sequestrectomy according to Williams. Neurosurgery 49:329-334, 2001

32. Yorimitsu E, Chiba K, Toyama Y, Hirabayashi K: Long-term outcomes of standard discectomy for lumbar disc herniation: A follow-up study of more than 10 years. Spine 26:652-657, 2001 